\title{
Research
}

\section{Association of GP wellbeing and burnout with patient safety in UK primary care:}

\author{
a cross-sectional survey
}

\begin{abstract}
Background

GPs have particularly high levels of burnout and poor wellbeing. Although both are associated with poorer safety outcomes within secondary care, there have been no quantitative studies investigating this within primary care. Furthermore, little is known about how occupational demands, burnout and wellbeing, and patient safety are all associated
\end{abstract}

\section{Aim}

To investigate whether occupational variables (demands and support) are associated with patient safety outcomes in general practice through their influence on GP burnout and wellbeing

\section{Design and setting}

Cross-sectional survey in the UK between

March 2016 and August 2017.

\section{Method}

A total of 232 practising GPs completed an online or paper survey measuring burnout, wellbeing, occupational demands and support, and patient safety.

\section{Results}

In all, 93.8\% of GPs were classed as likely to be suffering from a minor psychiatric disorder, $94.7 \%$ as suffering from mild (22.0\%) or severe $(72.7 \%)$ exhaustion, and $86.8 \%$ as having mild (37.9\%) or severe (48.9\%) disengagement. Structural equation modelling (SEM) analyses showed that spending a higher number of hours on administrative tasks and on call, and feeling less supported in their practice, was associated with lower wellbeing, which in turn was associated with a higher likelihood of having reported a near miss in the previous 3 months. A higher number of hours spent on administrative tasks, a higher number of patients seen per day, and feeling less supported were associated with higher burnout levels, which in turn was associated with worse perceptions of safety.

\section{Conclusion}

To improve patient safety within general practice changes could be made at both practice and individual levels to promote a healthier work environment for staff and patients.

\section{Keywords}

burnout; general practice; general practitioners; patient safety; professional; support; wellbeing.

\section{INTRODUCTION}

GPs have high rates of burnout and poor mental wellbeing compared with the general population and other healthcare professionals. $^{1-11}$ In the UK, GPs are experiencing the highest stress levels since $1998{ }^{12}$ there is an alarming workforce shortage and large numbers are considering leaving the profession. ${ }^{12,13}$

In general, burnout and poor wellbeing in healthcare professionals is associated with poorer patient safety outcomes, such as increased risk of adverse events and near misses, ${ }^{14-16}$ but this area is under researched within primary care. Given the high levels of burnout and frequency of patient safety incidents within this setting, this research is imperative: up to $2 \%$ of GP consultations result in patient safety incidents, ${ }^{17}$ and $12 \%$ of patients are subject to prescription errors. ${ }^{18}$ Despite a lack of quantitative research, recent qualitative studies indicate that GPs perceive that burnout and poor wellbeing negatively impacts their ability to deliver safe care. ${ }^{19}$

Various occupational factors contribute to GP burnout and wellbeing, including increased paperwork and patient demands, and lack of support. ${ }^{20,21}$ Occupational demands are also associated with safety outcomes within secondary care. However, less is known about how occupational demands, burnout and wellbeing, and patient safety are all associated. One study of nurses suggests burnout mediates the association

LH Hall, PhD, research fellow; J Johnson, PhD ClinPsyD, lecturer, School of Psychology, University of Leeds, Leeds, and Yorkshire Quality and Safety Research Group, Bradford Institute for Health

Research, Bradford, Bradford. DB O'Connor, PhD, professor of psychology, School of Psychology, University of Leeds, Leeds. I Watt, MPH, FFPH, professor of primary and community care, Department of Health Sciences, University of York, York, and Hull York Medical School, York. Address for correspondence Louise H Hall, Level 10 Worsley Building, Leeds between occupational variables and patient safety outcomes. ${ }^{22}$

The current study therefore aimed to investigate whether occupational variables related to demands and support are associated with patient safety outcomes in general practice, through their influence on GP burnout and wellbeing. It had four main aims, to determine whether:

- occupational characteristics are associated with burnout and wellbeing in GPs;

- GP burnout and wellbeing are associated with patient safety;

- occupational characteristics are associated with patient safety; and

- GP burnout and wellbeing mediate any associations between occupational characteristics and patient safety.

\section{METHOD}

Design

A cross-sectional survey design was used, undertaken between March 2016 and August 2017.

\section{Participants and recruitment strategy}

Currently practising UK GPs were eligible. Participants were recruited for an online version of the questionnaire either via a previous study, Twitter, GP media outlets, GP-related professional bodies (British Medical Association [BMA]), or practice managers. Paper questionnaires were posted

Institute of Health Sciences, University of Leeds, Leeds LS2 9JL, UK.

Email: L.H.Hallaleeds.ac.uk

Submitted: 7 Sep 2018; Editor's response: 9 Oct 2018; final acceptance: 12 Nov 2018. (CBritish Journal of General Practice This is the full-length article (published online 24 Apr 2019) of an abridged version published in print. Cite this version as: Br J Gen Pract 2019; DOI: https://doi.org/10.3399/bjgp19X702713 


\section{How this fits in}

Despite research demonstrating the association between healthcare professionals' levels of burnout and wellbeing with patient safety outcomes in secondary care, research within primary care is lacking. This study is the first to establish the association between these variables in general practice. Occupational demands and support were found to be associated with patient safety (outcomes and perceptions) through their impact on GPs' levels of burnout and wellbeing. Changes at both practice and individual levels could be made to provide a healthier work environment for staff and safer care for patients.

to a random selection of GPs from a publicly available nationwide database (egpcur), with pre-paid return envelopes.

\section{Measures}

Demographics lage, sex, ethnicity, and years working as a GP) and measures of occupational characteristics, burnout, wellbeing, and patient safety were collected.

\section{Occupational characteristics}

Work demands characteristics were measured (Table 1). Additionally, participants rated how supported they felt within their workplace on an 11-point analogue scale from 0 ('not at all supported') to 10 ('very supported').

\section{Burnout}

The 16-item Oldenburg burnout inventory (OLBI) measured burnout on two subscales (exhaustion and disengagement). ${ }^{23,24}$ Scores on each scale were categorised into: "no exhaustion/disengagement', (0-17.59), 'mild exhaustion/disengagement' (17.60-21.99), and 'severe exhaustion/disengagement' (2232). 25,26

\section{Wellbeing}

The 12-item general health questionnaire (GHQ-12) measured general wellbeing. ${ }^{27}$ Higher scores indicated poorer mental wellbeing; scores $>3$ were categorised as a possible case of minor psychiatric illness. ${ }^{28} \mathrm{~A}$ quality of life linear analogue scale measured

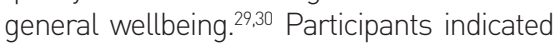
how satisfied they currently were with their life overall from 0 ('as bad as it could be') to 10 ('as good as it could be').

\section{Patient safety}

Adverse events and near misses. Participants reported whether they had been responsible for any adverse events (AEs) or near misses (NMs) in the previous 3 months ('yes' or 'no' for each question). ${ }^{31-35}$ If 'yes' for either, they were asked to classify the outcome, type, and contributing factor of the AE/NM. ${ }^{34,36-39}$

Safe practitioner. The 'safe practitioner' measure was used. Participants rated the extent they felt they delivered a safe practice in general, dependent on work-related conditions. ${ }^{40,4}$

Data analysis and preparation. Responses were screened for outliers and eligibility. Two cases were removed due to ineligibility, three due to large amounts of missing data $(>20 \%)$, and one outlier was edited in line with recommended guidelines. ${ }^{42}$ The remaining data $(n=227)$ contained some missing data points, but these data points were missing completely at random $\left(\chi^{2}=616.609\right.$, degrees of freedom [df] 611, $P=0.429$ ). ${ }^{43}$ Each variable did not exceed more than $6 \%$ missing data.

For SPSS-22 analyses, missing data were imputed using multiple imputation (five iterations). For analyses in AMOS-22, the inbuilt regression imputation method was used. Descriptive statistics and bivariate correlations were conducted in SPSS-22.

For aims 1-3, regressions models were tested in STATA, allowing pooling of regression outputs using the imputed datasets.44 For aim 4, structural equation models (SEM) were built and tested in AMOS so that bootstrapping could be applied and measurement errors controlled for. In all, 5000 bootstrap samples with a 95\% biascorrected confidence interval were used. The following criteria were selected for assessing model fit: $45.46 \chi^{2} P>0.05$, comparative fit index (CFI) $P>0.95$, root mean square error of approximation (RMSEA) $P<0.07$.

However, the significance of the $\chi^{2}$ statistic should be interpreted with caution, as it is often significant with samples $>200$ and when the model contains large correlations. ${ }^{46}$ For all regression models and SEM analyses, age, sex, and years working as a GP were controlled for. Regressions in STATA were conducted both with and without these control variables, and $R^{2}$ change was calculated. Outputs for the regressions inclusive of control variables are reported.

\section{RESULTS}

\section{Participants}

In all, 232 GPs participated. Around 20 GPs were recruited following participation in a previous study or from Twitter. The majority ( $n$, 180) were recruited via the BMA, who provided a link to the survey on their online GP forum and emailed this to their 
subscribers. Remaining participants were recruited through postal surveys and by emailing practice managers.

\section{Descriptive statistics}

Descriptive statistics prior to missing data imputation are reported in Table 1. Pearson's, Spearman's, and point-biserial correlations, are available from the authors on request. Job role responses were recoded into a dichotomous variable to allow comparison between partners versus all other roles.

A total of $94.7 \%$ of participants were classed as having mild (22.0\%) or severe (72.7\%) exhaustion, and $86.8 \%$ as having mild (37.9\%) or severe (48.9\%) disengagement. In all, 93.8\% of participants were classed as likely to be suffering from a minor psychiatric disorder.

Almost half of all participants (44.1\%) reported a near miss in the previous 3 months, and one-sixth (15.9\%) reported an adverse event. Medication or prescription AE/NM were the most common, followed by communication AE/NM. The majority of AEs and NMs resulted in lor had the potential to result in) minor reversible harm. One $\mathrm{AE}$ resulted in major irreversible harm, and six NMs had the potential to result in major irreversible harm. The most commonly cited contributors were GP's fatigue, concentration lapse, and burnout (further information available from the authors on request).

\section{Aims 1-3}

Multiple and logistic regressions were conducted to address aims 1-3. Model statistics lincluding significant predictor variables) are reported in Tables 2 and 3 . Occupational variables explained a significant amount of variance in burnout, wellbeing, and safe practitioner scores. Hours on call and $\mathrm{GHQ}$ scores explained a significant amount of variance in near misses. Burnout (specifically exhaustion) explained a significant amount of variance in safe practitioner scores.

\section{Aim 4: Modelling all variables}

Three SEMs were tested using AMOS to determine whether wellbeing and burnout mediated the association between occupational variables and patient safety

\section{Table 1. Descriptive statistics}

\begin{tabular}{|c|c|c|c|c|}
\hline Variable & $N^{a}$ & Mean (SD) & Range & Frequencies, $n(\%)$ \\
\hline $\mathrm{Age}^{\mathrm{a}}$ & 223 & $47.86(10.691)$ & $27-66$ & \\
\hline Sex & 227 & & & Female, $n=135$ (59.5), male, $n=89$ (39.2), undisclosed, $n=3,(1.3)$ \\
\hline Years in practice & 227 & $17.97(9.841)$ & $0-55$ & \\
\hline Job role & 227 & & & $\begin{array}{l}\text { Partner, } n=157 \text { (69.2), locum, } n=12 \text { (5.3), salaried, } n=41 \text { (18.1), } \\
\text { other, } n=13 \text { (for example, in training) (5.7), undisclosed, } n=4,(1.8)\end{array}$ \\
\hline Practice location & 227 & & & $\begin{array}{l}\text { Urban, } n=81 \text {, (35.7), suburban, } n=97 \text { (42.7), rural, } n=36 \text { (15.9), } \\
\text { mixed, } n=13 \text { (5.7) }\end{array}$ \\
\hline Patient contact hours per week & 227 & $23.278(10.09)$ & $0-50$ & \\
\hline Patients seen per day & 222 & $32.77(7.963)$ & $9-51$ & \\
\hline Extra roles per weeka & 214 & $4.322(6.524)$ & $0-35$ & \\
\hline Admin hours per week & 227 & 11.850 (7.579) & $0-36$ & \\
\hline Antisocial hours per week & 227 & $9.22(6.153)$ & $0-36$ & \\
\hline On call per montha & 214 & $21.63(28.339)$ & $0-160$ & \\
\hline Supportive practice & 227 & $6.33(2.575)$ & $0-10$ & \\
\hline Safe practice & 227 & $2.26(1.188)$ & $0-4$ & \\
\hline Quality of life & 227 & $5.80(2.02)$ & $0-10$ & \\
\hline $\mathrm{GHQ}-12^{\mathrm{a}}$ & 223 & $7.91(2.605)$ & $0-12$ & Possible case, $n=209$, (93.72), no case, $n=14,(6.28)$ \\
\hline OLBI: $E^{a}$ & 222 & $23.98(3.952)$ & $13-32$ & None, $n=12,(5.41)$, mild, $n=48,(21.62)$, severe, $n=162$, (72.97) \\
\hline OLBI: $D^{a}$ & 224 & $21.48(3.582)$ & $13-32$ & None, $n=29$ (12.95), mild, $n=84$ (37.50), severe, $n=111$ (49.55) \\
\hline OLBI: total score & 220 & $45.47(6.729)$ & $28-64$ & \\
\hline Adverse events & 227 & & & $\geq 1, n=36(15.9), 0, n=190$ (83.7), missing data, $n=1(0.4)$ \\
\hline Near miss & 227 & & & $\geq 1, n=100(44.1), 0, n=127(55.9)$ \\
\hline
\end{tabular}

a Figures reported in Table 1 are prior to missing data being imputed, whereas the reported figures in the text are after missing data was imputed, which is why they are slightly different. $G H Q=$ general health questionnaire. $O L B I=$ Oldenburg burnout inventory. $O L B I: D=O l d e n b u r g$ burnout inventory: disengagement. OLBI: $E=O l d e n b u r g$ burnout inventory: exhaustion. $S D=$ standard deviation. 
Table 2. Regression outputs for burnout, wellbeing, and patient safety outcome variables (aims 1 and 3)

\begin{tabular}{|c|c|c|c|c|c|c|c|c|c|c|c|c|}
\hline & $\begin{array}{c}\text { Model } \\
\text { F statistic }\end{array}$ & $\begin{array}{l}\text { Model } \\
P \text {-value }\end{array}$ & $\begin{array}{c}\text { Model } \\
\mathbf{R}^{2} \text { (mean) }\end{array}$ & Job role & $\begin{array}{l}\text { Practice } \\
\text { list size }\end{array}$ & $\begin{array}{c}\text { Antisocial } \\
\text { hours }\end{array}$ & $\begin{array}{l}\text { Admin } \\
\text { hours }\end{array}$ & $\begin{array}{l}\text { Extra } \\
\text { roles }\end{array}$ & On call & $\begin{array}{l}\text { Patients } \\
\text { per day }\end{array}$ & $\begin{array}{c}\text { Patient } \\
\text { contact } \\
\text { hours }\end{array}$ & $\begin{array}{c}\text { Supportive } \\
\text { practice }\end{array}$ \\
\hline Safe practitioner & 1.90 & 0.035 & 0.101 & -0.047 & -0.100 & -0.149 & $0.323^{\mathrm{a}}$ & 0.095 & -0.010 & 0.028 & -0.005 & -0.003 \\
\hline PSI & 1.14 & 0.318 & $\mathrm{n} / \mathrm{a}$ & 1.131 & 1.000 & 0.987 & 0.973 & 0.961 & $0.987^{b}$ & 0.996 & 1.01 & 1.039 \\
\hline Adverse event ${ }^{d}$ & 0.61 & 0.837 & $\mathrm{n} / \mathrm{a}$ & 1.154 & 1.000 & 0.953 & 0.990 & 0.990 & 0.997 & 0.998 & 0.996 & 1.048 \\
\hline Near miss ${ }^{d}$ & 1.36 & 0.179 & $\mathrm{n} / \mathrm{a}$ & 1.060 & 1.000 & 0.984 & 0.976 & 0.959 & $0.983^{c}$ & 1.015 & 1.008 & 1.072 \\
\hline OLBI: D & 6.60 & $<0.001$ & 0.275 & -0.126 & 0.028 & -0.069 & $0.165^{b}$ & 0.066 & -0.105 & $0.154^{b}$ & 0.046 & $-0.396^{a}$ \\
\hline OLBI: E & 5.77 & $<0.001$ & 0.249 & -0.078 & 0.106 & 0.063 & $0.200^{c}$ & 0.097 & -0.075 & 0.085 & 0.004 & $-0.346^{a}$ \\
\hline $\mathrm{GHQ}-12$ & 5.87 & $<0.001$ & 0.252 & -0.129 & 0.026 & -0.049 & $0.233^{c}$ & 0.077 & 0.067 & 0.026 & 0.120 & $-0.301^{a}$ \\
\hline QoL & 9.20 & $<0.001$ & 0.345 & -0.001 & 0.026 & 0.026 & $-0.227^{c}$ & $-0.210^{a}$ & 0.033 & $-0.137^{b}$ & $-0.237^{a}$ & $0.339^{a}$ \\
\hline
\end{tabular}

Variables listed vertically indicate model outcome variables. Variables listed horizontally indicate predictor variables. Bold font indicates significant models and variables. a Variable made a significant independent contribution to the model at $\mathrm{P}<0.001 .{ }^{b}$ Variable made a significant independent contribution to the model at $P<0.05$. ${ }^{c}$ Variable made a significant independent contribution to the model at $P<0.01$. ${ }^{\mathrm{d}}$ Logistic regression. $G H Q=$ general health questionnaire. $n / a=n o t$ applicable. OLBI $=0 l d e n b u r g$ burnout inventory. $O L B I: D=$ Oldenburg burnout inventory: disengagement. OLBI: $E=$ Oldenburg burnout inventory: exhaustion. PSI = patient safety incident. QoL = quality of life. All regressions controlled for age, sex, and years in practice. Statistics represent mean standardised $\beta$ coefficients for linear regressions, odds ratios for logistic regressions.

outcomes. The occupational variables chosen for inclusion in each model were based on their significance in the previous regression models. If an occupational variable made a significant, independent contribution to either of the models with a wellbeing/burnout outcome variable or the models with a patient safety outcome variable, it was included in the relevant SEM (Table 2). Age, sex, and years working as a GP were controlled for in all models. No model was tested using AEs as the outcome, due to a lack of significant associations in the previous regressions.

Model 1: Wellbeing and near misses

This model tested whether administrative hours, supportive practice, and on call were indirectly associated with near misses, with wellbeing mediating the association (Figure 1). The model was a good fit when the covariance between administrative hours and on call was controlled for $l \chi^{2}(11)=16.930$, $P=0.110, \mathrm{CFI}=0.984, \mathrm{RMSEA}=0.049,95 \%$ confidence intervals $[\mathrm{Cl}]=0.000$ to 0.092 ). This model suggests that working in less supportive practices and spending a high number of hours on administrative work were associated with poorer wellbeing, which in turn was associated with a higher likelihood of being involved in a near miss.

Model 2: Burnout and safe practitioner The second model tested whether administrative hours, supportive practice,

Table 3. Regression outputs indicating whether burnout and wellbeing variables explain safety outcomes (aim 2)

\begin{tabular}{|c|c|c|c|c|c|c|c|c|}
\hline & $\begin{array}{c}\text { Model } \\
\text { F statistic }\end{array}$ & $\begin{array}{l}\text { Model } \\
P \text {-value }\end{array}$ & $\begin{array}{c}\text { Model } \\
\mathbf{R}^{2} \text { (mean) }\end{array}$ & OLBI & OLBI: D & OLBI: E & GHQ-12 & QoL \\
\hline Safe practitioner ${ }^{a}$ & 3.58 & 0.002 & 0.091 & $0.267^{c}$ & - & - & 0.019 & -0.014 \\
\hline Safe practitionerb & 5.02 & $<0.001$ & 0.105 & - & 0.015 & $0.300^{d}$ & - & - \\
\hline PSI ${ }^{e}$ & 1.33 & 0.242 & $n / a$ & 1.012 & - & - & 0.881 & 1.078 \\
\hline Adverse evente & 0.79 & 0.576 & n/a & 0.980 & - & - & 0.940 & 1.063 \\
\hline Near miss ${ }^{e}$ & 1.44 & 0.196 & $n / a$ & 1.021 & - & - & $0.856^{f}$ & 1.070 \\
\hline
\end{tabular}

Variables listed vertically indicate model outcome variables. Variables listed horizontally indicate predictor variables. Bold font indicates significant models and variables. aModel included only total OLBI score and not scores from the two separate scales. ${ }^{b}$ Model included disengagement scores and exhaustion scores, but not total OLBI score. ${ }^{c}$ Variable made a significant independent contribution to the model at $P<0.01$. ${ }^{\circ}$ Variable made a significant independent contribution to the model at $P<0.001$. ${ }^{2} L o g i s t i c$ regression. 'Variable made a significant independent contribution to the model at $P<0.05$. All regressions controlled for age, sex, and years in practice. Statistics represent mean standardised $\beta$ coefficients for linear regressions, odds ratios for logistic regressions. $G H Q=$ general health questionnaire. $n / a=$ not applicable. $O L B I=$ Oldenburg burnout inventory. OLBI: $D=$ Oldenburg burnout inventory: disengagement. OLBI: $E=$ Oldenburg burnout inventory: exhaustion. $P S I=$ patient safety incident. QoL = quality of life. 


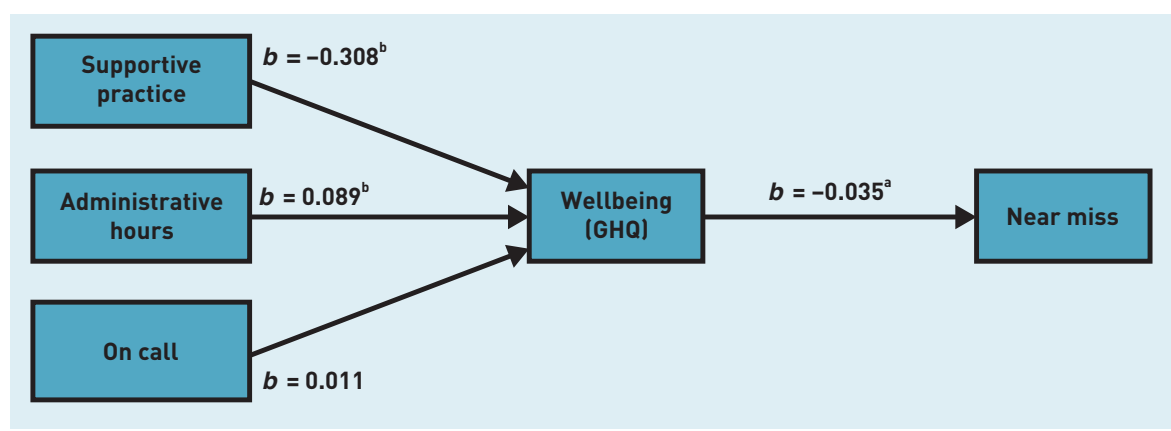

Figure 1. Occupational variables, wellbeing, and near misses. $b=$ unstandardised beta. ${ }^{a} \mathrm{P}<0.01 .{ }^{b} \mathrm{P}<0.001$. $G H Q=$ general health questionnaire.

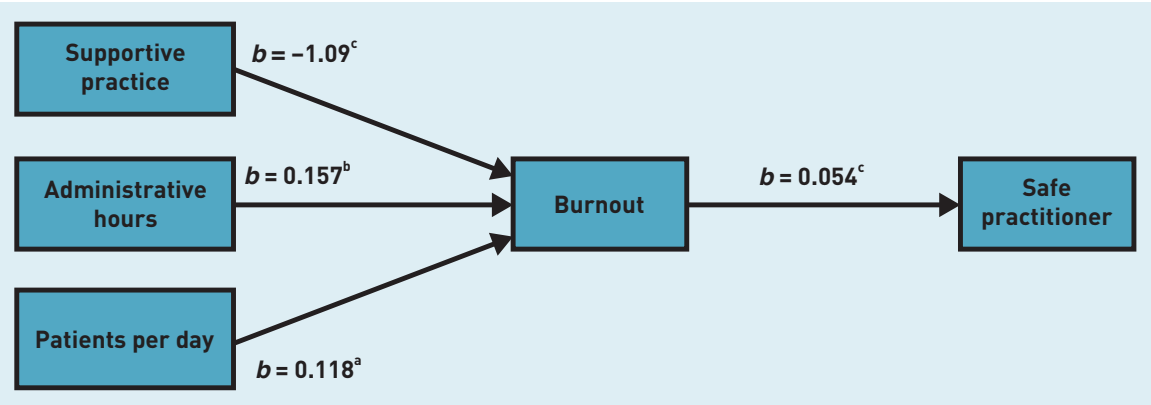

Figure 2. Occupational variables, burnout, and safe practitioner. $b=$ unstandardised beta. ${ }^{a} \mathrm{P}<0.05 .{ }^{b} \mathrm{P}<0.01$. ${ }^{\mathrm{P}}<0.001$.

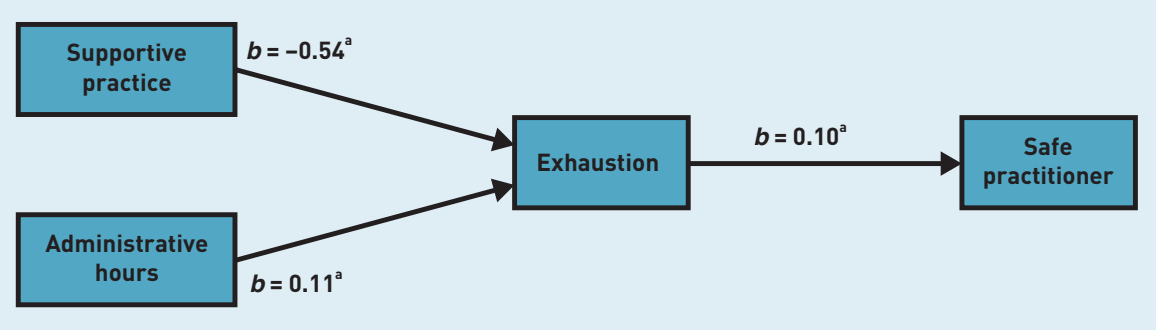

Figure 3. Occupational variables, exhaustion, and safe practitioner. $b=$ unstandardised beta. ${ }^{a} \mathrm{P}<0.001$.
(Figure 3). This model was found to be of adequate fit according to most of the fit indices $\left(\chi^{2}(9)=17.748, P=0.038, C F I=0.977\right.$ RMSEA $=0.066,95 \% \mathrm{Cl}=0.015$ to 0.110 ). This model suggests that a higher number of hours spent on administrative work and a less supportive practice were associated with exhaustion, which in turn was associated with lower safety perceptions.

\section{DISCUSSION}

\section{Summary}

An alarmingly high number of GPs in this sample reported mild to severe levels of burnout, and high scores on the GHQ-12, indicating possible cases of minor psychiatric illness. SEM models demonstrated that specific occupational variables were associated with patient safety outcomes, through their influence on wellbeing and burnout. Specifically, spending a higher number of hours on administrative tasks and on call, and feeling less supported, was associated with lower wellbeing, which in turn was associated with a higher likelihood of reporting a near miss in the previous 3 months.

Additionally, a higher number of hours spent on administrative tasks, a higher number of patients seen per day, and feeling less supported was associated with higher burnout levels, which in turn was associated with worse perceptions of safety. Furthermore, a higher number of hours spent on administrative tasks and not feeling well-supported was associated with greater feelings of exhaustion (a burnout subfacet), which in turn was associated with worse perceptions of safety.

All models found that hours spent on administrative tasks and the amount of support in the practice were significantly indirectly associated with patient safety loutcomes and perceptions), indicating that these two occupational variables are perhaps the most important when it comes to GPs wellbeing, burnout levels, and patient safety.

To improve patient safety within general practices, changes could be made at both the practice level and the individual level to promote a healthier work environment for staff and patients.

\section{Strengths and limitations}

This is the first quantitative study demonstrating associations between occupational characteristics, burnout, wellbeing, and patient safety within GPs. Previous literature discussing these links in this setting has solely been qualitative. 19,21,47 Another strength is the use of wellbeing and burnout measures simultaneously within 


\section{Funding}

The research was supported by the National Institute for Health Research (NIHR) Collaboration for Leadership in Applied Health Research and Care (CLAHRC) Yorkshire and Humber. The views expressed are those of the authors, and not necessarily those of the NHS, the NIHR, or the Department of Health and Social Care. (Reference: NIHR IS-CLA-0113-10020).

\section{Ethical approval}

This study received ethical approval from the University of Leeds, School of Psychology Ethics Committee (ref \#16-0191 accepted on 19/07/2016) and the Health Research Authority (IRAS ref \#207249).

\section{Provenance}

Freely submitted; externally peer reviewed.

\section{Competing interests}

The authors have declared no competing interests.

\section{Acknowledgments}

The authors wish to thank all of the GPs who took part in this study for giving their time freely. They also thank the British Medication Association for helping to advertise this study.

\section{Open access}

This article is Open Access: CC BY-NC 4.0 license (http://creativecommons.org/ licenses/by-nc/4.0/).

\section{Discuss this article}

Contribute and read comments about this article: bjgp.org/letters analyses. The importance of measuring both has previously been highlighted. ${ }^{14}$

This study had a relatively small sample size, due to recruitment difficulties. The cross-sectional design limits the ability to determine cause and effect. It is possible that more hours spent on administrative work does not cause burnout, but that burnt out GPs are struggling to cope with the workload and therefore take longer to complete paperwork than those who are not struggling. For a true test of the mediating role of burnout and wellbeing, occupational variables, burnout and wellbeing, and safety should be assessed over time. Although the current study cannot comment on the direction of these relationships, establishing that these variables are associated is a necessary first step, before future research can establish the direction.

Finally, participants were self-selecting, with the majority belonging to the trade union for doctors in the UK (the BMA), which causes potential for a biased sample and therefore has implications for the generalisability of the results. In particular, the self-selecting nature of the sample may partially explain the exceedingly high proportion of participants reporting high levels of burnout and mental distress. Although previous surveys also reported fairly high rates of GP burnout and mental illness, ${ }^{6,7}$ it may be worth investigating whether more conservative screening tools are needed in this population, or whether these high rates indicate a serious and pervasive mental health concern for current and future GPs.

\section{Comparison with existing literature}

These results are consistent with literature regarding secondary care doctors that suggests that poorer wellbeing and burnout are associated with patient safety measures. ${ }^{14-16}$ They also provide quantitative support for previous qualitative findings by Hall et al within general practice. ${ }^{19}$

The variables found to be commonly associated with all of the burnout and wellbeing measures were the number of hours spent on administrative work per week, and the level of support within the practice. These findings support previous studies based on the job demands control and job demands resources theories of burnout. These theories posit that work environments with high demands ffor example, heavy workloads, long hours, and high pressure) and low levels of either job control luse of skills and autonomy at work] or job resources (for example, peer and managerial support, or physical resources) are conducive to employee stress, ill-health, and burnout. ${ }^{26,48}$

These findings also support previous qualitative research reporting that GPs have stated a need for a reduction in administrative work, or for more administrative support staff. 21,47 Paperwork was the fourth biggest stressor in a UK GP survey in 2015,12 and has historically been a major stressor for GPs..$^{49}$ Furthermore, it is well acknowledged that levels of support are important to staff wellbeing and burnout levels across all sectors, including health care. ${ }^{50-52}$

Fostering a more positive and supportive team culture through formal (for example, mentoring systems) or informal (for example, communal breaks) ways should be a serious consideration among practice staff and healthcare organisation managers.

These findings support previous research within secondary care among Canadian nurses that reported that work environments (including support) were associated with adverse events through the key mediating role of burnout. 22

The current study adds to this, and shows that it is the level of support and the amount of administrative work in particular that impact on burnout and wellbeing, and subsequently lead to changes in safety.

\section{Implications for research and practice}

These findings suggest two places that interventions could target. One is at system or practice level by addressing the occupational characteristics; that is, reducing administrative work, hiring more administrative staff, providing a more supportive environment. The second is at an individual level; for example, through resilience training. Both have advantages and disadvantages. It is likely that a dual approach is needed to successfully reduce burnout, improve wellbeing, and also reduce patient safety incidents.

Cost-effectiveness evaluations of the relative approaches are warranted to help identify the most feasible solutions. It is likely to be more cost-effective to intervene on these issues than not to; the Boorman Report estimates that improving staff health and wellbeing in primary care could save €213 806 annually per trust. ${ }^{53}$

Future research should take a longitudinal approach to understand temporal relationships between these variables, within a larger sample of GPs. This will clarify whether burnout and poor wellbeing lead to poorer patient safety, whether the reverse is true, or whether it is a vicious circle. 


\section{REFERENCES}

1. Arigoni F, Bovier PA, Mermillod B, et al. Prevalence of burnout among Swiss cancer clinicians, paediatricians and general practitioners: who are most at risk? Support Care in Cancer 2009; 17(1): 75-81

2. Arigoni F, Bovier PA, Sappino A-P. Trend of burnout among Swiss doctors. Swiss Med Wkly 2010; 140: w13070.

3. O'Connor DB, O'Connor RC, White BL, Bundred PE. The effect of job strain on British general practitioners' mental health. J Ment Health 2000; 9(6): 637-654.

4. Klersy C, Callegari A, Martinelli V, et al. Burnout in health care providers of dialysis service in Northern Italy - a multicentre study. Nephrol Dial Transplant 2007; 22(8): 2283-2290.

5. Lee FJ, Stewart M, Brown JB. Stress, burnout, and strategies for reducing them What's the situation among Canadian family physicians? Can Fam Physician 2008; 54(2): 234-235.

6. McManus I, Jonvik H, Richards P, Paice E. Vocation and avocation: leisure activities correlate with professional engagement, but not burnout, in a crosssectional survey of UK doctors. BMC Med 2011; 9(1): 100.

7. Orton P, Orton C, Pereira Gray D. Depersonalised doctors: a cross-sectional study of 564 doctors, 760 consultations and 1876 patient reports in UK general practice. BMJ Open 2012; 2(1): e000274.

8. Poncet MC, Toullic P, Papazian L, et al. Burnout syndrome in critical care nursing staff. Am J Respir Crit Care Med 2007; 175(7): 698-704.

9. Ramirez A, Graham J, Richards M, et al. Burnout and psychiatric disorder among cancer clinicians. Br J Cancer 1995; 71(6): 1263-1269.

10. Ross J, Jones J, Callaghan $P$, et al. A survey of stress, job satisfaction and burnout among haemodialysis staff. J Ren Care 2009; 35(3): 127-133.

11. Soler JK, Yaman H, Esteva M, et al. Burnout in European family doctors: the EGPRN study. Fam Pract 2008; 25(4): 245-265.

12. Gibson J, Checkland K, Coleman A, et al. Eighth national GP worklife survey 2015. https://www.research.manchester.ac.uk/portal/en/publications/eighthnational-gp-worklife-surveyla76ed99e-c54e-4ba4-a20e-ce432322689el/export html laccessed 16 Apr 2019).

13. British Medical Association. Quarterly tracker survey: Current views from across the medical profession Quarter 2, June 2017. BMA 2017.

14. Hall LH, Johnson J, Watt I, et al. Healthcare staff wellbeing, burnout, and patient safety: A systematic review. PLoS One 2016; 11(7): e0159015.

15. Salyers MP, Bonfils KA, Luther $L$, et al. The relationship between professional burnout and quality and safety in healthcare: a meta-analysis. J Gen Intern Med 2017; 32(4): 475-482

16. Welp A, Manser T. Integrating teamwork, clinician occupational well-being and patient safety - development of a conceptual framework based on a systematic review. BMC Health Serv Res 2016; 16(1): 281

17. Gaal S, Verstappen W, Wolters R, et al. Prevalence and consequences of patient safety incidents in general practice in the Netherlands: a retrospective medical record review study. Implement Sci 2011; 6(1): 37.

18. Avery AA, Barber N, Ghaleb M, et al. Investigating the prevalence and causes of prescribing errors in general practice: the PRACtICe study. London: General Medical Council, 2012

19. Hall LH, Johnson J, Heyhoe J, et al. Exploring the impact of primary care physician burnout and wellbeing on patient care: a focus group study. J Patient Saf 2017; DOI: 10.1097/PTS.0000000000000438.

20. Cheshire A, Ridge D, Hughes J, et al. Influences on GP coping and resilience: a qualitative study in primary care. Br J Gen Pract 2017; DOI: https://doi. org/10.3399/bjgp17X690893.

21. Hall LH, Johnson J, Heyhoe J. Strategies to improve general practitioner wellbeing: a focus group study. Fam Pract 2017; DOI: 10.1093/fampra/cmx130.

22. Laschinger HKS, Leiter MP. The impact of nursing work environments on patient safety outcomes: the mediating role of burnout engagement. J Nurs Adm 2006; 36(5): 259-267.

23. Demerouti E, Bakker AB, Vardakou I, Kantas A. The convergent validity of two burnout instruments: a multitrait-multimethod analysis. Eur J Psychol Assess 2003; 19(1): 12-23.

24. Halbesleben JR, Demerouti E. The construct validity of an alternative measure of burnout: investigating the English translation of the Oldenburg burnout inventory. Work \& Stress 2005; 19(3): 208-220

25. Björklund C, Jensen I, Lohela-Karlsson M. Is a change in work motivation related to a change in mental well-being? J Vocat Behav 2013; 83(3): 571-580.
26. Demerouti E, Bakker AB, Nachreiner F, Schaufeli WB. The job demandsresources model of burnout. J Appl Psychol 2001; 86(3): 499-512.

27. Goldberg DP. The detection of psychiatric illness by questionnaire: a technique for the identification and assessment of non-psychotic psychiatric illness. Oxford: Oxford University Press, 1972.

28. Hardy GE, Shapiro DA, Haynes CE, Rick JE. Validation of the general health questionnaire-12: Using a sample of employees from England's health care services. Psychol Assess 1999; 11(2): 159-165.

29. West CP, Huschka MM, Novotny PJ, et al. Association of perceived medical errors with resident distress and empathy: a prospective longitudinal study. JAMA 2006; 296(9): 1071-1078.

30. West CP, Tan AD, Habermann TM, et al. Association of resident fatigue and distress with perceived medical errors. JAMA 2009; 302(12): 1294-1300.

31. Arimura M, Imai M, Okawa M, et al. Sleep, mental health status, and medical errors among hospital nurses in Japan. Ind Health 2010; 48(6): 811-817.

32. Baldwin P, Dodd M, Wrate R. Young doctors' health - I. How do working conditions affect attitudes, health and performance? Soc Sci Med 1997; 45(1): $35-40$.

33. De Oliveira Jr GS, Chang R. Fitzgerald PC, et al. The prevalence of burnout and depression and their association with adherence to safety and practice standards: a survey of United States anesthesiology trainees. Anesth Analg 2013; 117(1): 182-193.

34. Shanafelt TD, Balch CM, Bechamps G, et al. Burnout and medical errors among American surgeons. Ann Surg 2010; 251(6): 995-1000.

35. Tanaka M, Tanaka K, Takano T, et al. Analysis of risk of medical errors using structural-equation modelling: a 6-month prospective cohort study. BMJ Qual Saf 2012; 21(9): 784-790

36. Dovey S, Meyers D, Phillips R, et al. A preliminary taxonomy of medical errors in family practice. Qual Saf Health Care 2002; 11(3): 233-238.

37. Esmail A. Measuring and monitoring safety: a primary care perspective. 2013. https://www.health.org.uk/sites/default/files/ MeasuringAndMonitoringSafetyAPrimaryCarePerspective.pdf laccessed 16 Apr 2019).

38. Rubin G, George A, Chinn D, Richardson C. Errors in general practice: development of an error classification and pilot study of a method for detecting errors. Qual Saf Health Care 2003; 12(6): 443-447.

39. Sandars J, Esmail A. The frequency and nature of medical error in primary care: understanding the diversity across studies. Fam Pract 2003; 20(3): 231236 .

40. Johnson J, Louch G, Dunning A, et al. Burnout mediates the association between depression and patient safety perceptions: a cross-sectional study in hospital nurses. J Adv Nurs 2017; 73(7); 1667-1680.

41. Louch G, O'Hara J, Gardner P, O'Connor DB. The daily relationships between staffing, safety perceptions and personality in hospital nursing: A longitudinal on-line diary study. Int J Nurs Stud 2016; 59: 27-37.

42. Field A. Discovering statistics using SPSS. $3^{\text {rd }}$ ed. Thousand Oaks, CA: Sage Publications, 2009

43. Little RJ. A test of missing completely at random for multivariate data with missing values. J Am Stat Assoc 1988; 83(404): 1198-1202.

44. Rubin DB. Multiple imputation for nonresponse in surveys. Somerset, NJ: J Wiley \& Sons, 1987.

45. Hooper D, Coughlan J, Mullen M. Structural equation modelling: guidelines for determining model fit. The Electronic Journal of Business Research Methods 2008; 6(1): 53-60.

46. Kenny DA. Measuring model fit. 2015. davidakenny.net/cm/fit.htm laccessed 16 Apr 2019).

47. Croxson $\mathrm{CH}$, Ashdown HF. Hobbs FR. GPs' perceptions of workload in England: a qualitative interview study. Br J Gen Pract 2017; DOI: https://doi.org/10.3399/ bjgp17X688849.

48. Karasek Jr RA. Job demands, job decision latitude, and mental strain: Implications for job redesign. Admin Sci Q 1979; 24: 285-308.

49. Appleton $\mathrm{K}$, House A, Dowell A. A survey of job satisfaction, sources of stress and psychological symptoms among general practitioners in Leeds. $\mathrm{Br} J \mathrm{Gen}$ Pract 1998; 48(428): 1059-1063.

50. Kinman G. Wray S, Strange C. Emotional labour, burnout and job satisfaction in UK teachers: the role of workplace social support. Educ Psychol 2011; 31(7): 843-856

51. Park K-O, Wilson MG, Lee MS. Effects of social support at work on depression 
and organizational productivity. Am J Health Behav 2004; 28(5): 444-455.

52. Sloan MM. Unfair treatment in the workplace and worker wellbeing: The role of coworker support in a service work environment. Work Occup 2012; 39(1): 3-34.
53. Boorman S. NHS health and wellbeing review: interim report. 2009. https:// webarchive.nationalarchives.gov.uk/20130103004910/http://www.dh.gov.uk/ en/Publicationsandstatistics/Publications/PublicationsPolicyAndGuidance/ DH 108799 (accessed 16 Apr 2019). 